\title{
Thermal Shock Behavior of Porous Nozzles with Various Pore Sizes for Continuous Casting Process
}

\author{
Juyoung Kim, Sanghyeon Yoon, Yoonho Kim*, and Heesoo Lee \\ School of Materials Science \& Engineering, Pusan National University, Busan 609-735, Korea \\ *Engine Development Department Platform Development Division Technical Center, Daihatsu Motor Co., Ltd, Shiga 520-2593, Japan
}

(Received October 4, 2011; Accepted November 18, 2011)

\begin{abstract}
Thermal shock behavior of porous ceramic nozzles with various pore sizes for continuous casting process of steel was investigated in terms of physical properties and microstucture. Porous nozzle samples with a composition of $\mathrm{Al}_{2} \mathrm{O}_{3}-\mathrm{SiO}_{2}-\mathrm{ZrO}_{2}$ were fabricated by adding various sizes of graphite as the pore forming agent. As the graphite size increased from $45 \sim 75$ to $150 \sim 180 \mu \mathrm{m}$, both the resulting pore size and the flexural strength also increased. A thermal shock test was carried out at temperatures $(\Delta \mathrm{T})$ of 600 , 700,800 , and $900^{\circ} \mathrm{C}$. Microstructure analysis revealed a small number of cracks on the sample with the largest mean pore size of $22.32 \mu \mathrm{m}$. In addition, increasing the pore size led to a smaller decrease in both pressure drop and elastic modulus. In conclusion, controlling the pore size can enhance thermal shock behavior.
\end{abstract}

Key words : Porous nozzle, Pore size, Thermal shock behavior, Mechanical properties, Microstructure

\section{Introduction}

orous ceramics have been used in many applications

$\mathrm{P}$ because they offer high thermal characteristics, excellent mechanical properties, and good chemical stability. ${ }^{1-5)}$ One high temperature applications of porous ceramics is the refractory industry, where, they are often exposed to rapid temperature changes causing thermal stress and the risk of thermal shock damages. ${ }^{6-8)}$

The thermal shock behavior of material can be estimated in two ways: theoretical calculation and/or experimental proof. ${ }^{8,9)}$ Thermal shock resistance is characterized by two parameters, $R$ and $R$ " ", defined by Hasselman ${ }^{10,11)}$ as shown below:

$$
\begin{aligned}
& R=\sigma_{f}(1-v) /(\alpha E) \\
& R ”,=\mathrm{EG}_{\mathrm{f}} / \sigma_{f}^{2}(1-v)
\end{aligned}
$$

where $\sigma_{\mathrm{f}}$ is the flexural strength, $v$ is the Poisson ratio, $E$ is the Young modulus of elasticity, $\alpha$ is the coefficient of thermal expansion, and $\mathrm{G}_{\mathrm{f}}$ is the fracture energy. $R$ and $R$ " " indicate the minimum thermal shock stress required to initiate a crack and the further thermal shock damage that will propagate the created cracks, respectively. ${ }^{10,11)}$ Depending on the equations, in order to improve thermal shock behavior, the required variances fluctuate with each other in terms of preventing

${ }^{\dagger}$ Corresponding author: Heesoo Lee

E-mail : heesoo@pusan.ac.kr

Tel : +82--51-510-2388 Fax : +82-51-512-0528 either crack initiation or propagation. Thus, many researchers have concentrated on improving thermal shock behavior with either one or both of these method. ${ }^{5-9)}$ For example, L. Shen et al. reported that thermal shock behavior could be improved by increasing porosity, since pores could relax the stress of thermal shock and arrest the propagation of microcracks. ${ }^{18)}$

In our previous study, the durability of porous nozzles with different porosities was investigated through a thermal shock test, ${ }^{12)}$ and an experimental approach was used to characterize the effects of pore size on the properties of porous nozzles. ${ }^{13)}$ For further investigation, we herein report how pore size can affect the thermal shock behavior of porous nozzles by preventing the propagation of cracks. To control the pore size, graphite was used as a pore forming agent. After a thermal shock test with a quenching media of water, the morphology of a porous nozzle with a $\mathrm{Al}_{2} \mathrm{O}_{3}-\mathrm{SiO}_{2}-\mathrm{ZrO}_{2}$ system was analyzed and the change of pressure drop $\mathrm{P}$ and elastic modulus E were investigated.

\section{Experimental Procedures}

Porous nozzle samples with various pore sizes were prepared with the same method as our previous study. ${ }^{13)}$ The starting powders were $\mathrm{Al}_{2} \mathrm{O}_{3}$ (AES-11, SUMITOMO, Japan) $92 \mathrm{wt} \%$, $\mathrm{SiO}_{2}$ (SIGMA-ALDRICH, USA) $4.5 \mathrm{wt} \%$, and $\mathrm{ZrO}_{2}$ (ZRO02PB, Kojundo Chemical Lab. Co.,Ltd, Japan) 3.5 wt\%. Graphite (KANTO Chemical, Japan) was used as a pore-forming agent and was classified into $45 \sim 75,100 \sim 125$, and 150 180 $\mu \mathrm{m}$ by sieving method. The graphite content was set by $20 \mathrm{wt} \%$ to make the porosity constant. After mixing and aging, the powders were formed into a disk shape (diameter of $25 \mathrm{~mm}$ ) and a bar shape $(50.24 \mathrm{~mm} \times 4.20 \mathrm{~mm} \times 7.35 \mathrm{~mm})$ under uniaxial 
pressure of $20 \mathrm{MPa}$, and were kept at room temperature for $48 \mathrm{~h}$. Sintering process was performed with two steps at $800^{\circ} \mathrm{C}$ for $2 \mathrm{~h}$ to burn out the graphite, and at $1550^{\circ} \mathrm{C}$ in an $\mathrm{E} / \mathrm{V}$ furnace for coarsening and densification.

Average pore size was calculated through image analysis technique. ${ }^{16)}$ Microstuctures analysis was carried out before and after the thermal shock test with scanning electron microscopy (HITACH S 4800). The bulk density and apparent porosity of the samples were determined via water immersion based on Archimedes' method. ${ }^{17)}$ A 3-point bending test (Universal Testing Machine, DUT-3000CM, KOREA) was employed and the results were defined by the standard equation, ${ }^{18)}$

$$
\sigma_{\mathrm{f}}=(3 \mathrm{PL}) /\left(2 \mathrm{bh}^{2}\right)
$$

where $\mathrm{P}$ is the fracture load, $\mathrm{L}$ the length of support span, $\mathrm{b}$ the sample width, and $\mathrm{h}$ the sample thickness. A thermal shock test with water quench method ${ }^{8)}$ was applied at $\Delta \mathrm{T}$ of $600,700,800$, and $900^{\circ} \mathrm{C}$. Sintered samples were continuously heated for $15 \mathrm{~min}$ at a selected temperature in an electric furnace and then put into a water bath at $25^{\circ} \mathrm{C}$ for $3 \mathrm{~min}$. Pressure drop was observed both before and after the thermal shock test in order to determine the permeability of the samples, and the dynamic modulus of elasticity $\mathrm{E}$ was also measured.

\section{Results and Discussion}

Table 1 shows the properties of the porous $\mathrm{Al}_{2} \mathrm{O}_{3}-\mathrm{SiO}_{2}-\mathrm{ZrO}_{2}$ system ceramics with controlled pore size. The average pore diameter of samples A, B, and C were 15.35, 19.42, and 22.32, respectively, which was in response to the size of graphite used as a pore forming agent. Apparent porosity and bulk

Table 1. Properties of Porous $\mathrm{Al}_{2} \mathrm{O}_{3}-\mathrm{SiO}_{2}-\mathrm{ZrO}_{2}$ System Ceramics with Controlled Pore Size

\begin{tabular}{lccc}
\hline \multicolumn{1}{c}{ Sample } & A & B & C \\
\hline Size of Added Graphite & $45-75(\mu \mathrm{m})$ & $100-125(\mu \mathrm{m}) 150-180(\mu \mathrm{m})$ \\
Average Pore Size $(\mu \mathrm{m})$ & 15.35 & 19.42 & 22.32 \\
Apparent Porosity $(\%)$ & 31.1 & 30.4 & 30.2 \\
Bulk Density $\left(\mathrm{g} / \mathrm{cm}^{2}\right)$ & 1.72 & 1.69 & 1.73 \\
Elastic Modulus $(\mathrm{GPa})$ & 8.94 & 8.73 & 10.81 \\
Flexural Strength $(\mathrm{MPa})$ & 5.33 & 5.98 & 6.54 \\
\hline
\end{tabular}

density were calculated by the following equations :

$$
\begin{aligned}
& \text { Bulk density }\left(\mathrm{g} / \mathrm{cm}^{3}\right)=\left(\mathrm{m}_{1} \mathrm{~d}\right) /\left(\mathrm{m}_{3}-\mathrm{m}_{2}\right) \\
& \text { Apparent porosity }(\%)=\left\{\left(\mathrm{m}_{3}-\mathrm{m}_{1}\right) /\left(\mathrm{m}_{3}-\mathrm{m}_{2}\right)\right\} \times 100
\end{aligned}
$$

where $\mathrm{m}_{1}, \mathrm{~m}_{2}$, and $\mathrm{m}_{3}$ are the mass of a dried sample in air (g), the sample in boiled water (g), and the sample with free bubbles on the surface (g), respectively. The values were approximately $30.45 \%( \pm 1 \%)$ and $1.705 \mathrm{~g} / \mathrm{cm}^{2}$. It seemed that these values were independent on pore size. Results show that this simple method of adding sieved pore-forming agents can control the pore size without any decrease of porosity or bulk density. As calculated by equation (3), sample $\mathrm{A}, \mathrm{B}$, and $\mathrm{C}$ had flexural strength of $5.33,5.98$, and $6.54 \mathrm{MPa}$, respectively. The flexural strength of the samples increased with increasing the pore size of the samples. This value showed the same tendency as increasing the pore size. In the literature, flexural strength decreases with increasing porosity, and the trend is more sensitive at low porosity until $30 \%{ }^{18,19)}$ Thus, our result could also be explained by the assumption of Rice, ${ }^{19)}$ who suggested that the fracture strength of porous ceramics is determined by the minimum solid area. When the porosity is kept constant, decreasing the pore size of the samples increases the number of pores, which creates narrower spaces between the pores. As shown in Fig. 1, the distance from pore to pore increased as the pore size increased. Consequently, the spaces become too thin to endure external stress, thus weakening the overall strength of the materials. ${ }^{13,19)}$

Fig. 2 shows SEM micrographs of the three samples (in the order of sample A, B, and C) after the thermal shock test at $600^{\circ} \mathrm{C}$ (Figs. 2(a), (b), and (c)) and $900^{\circ} \mathrm{C}$ (Figs. 2(d), (e), and (f)). All of the samples had small microcracks that seemed to start from the pores and propagate from there. In the micrographs after the thermal shock test at $900^{\circ} \mathrm{C}$, the cracks of all of the also appeared to propagate along the pores. When comparing these micrographs, however, the cracks in sample $\mathrm{C}$ grew less than the other samples, which could indicate that greater distance between pores in sample $\mathrm{C}$ hindered the propagation to other pores. This assumption is also in accordance with both the aforementioned and the following results.

Fig. 3 provides the pressure drop results for the samples. When $\Delta \mathrm{T}$ is $0^{\circ} \mathrm{C}$ (before the thermal shock test), the results were as similar to our previous study. ${ }^{13)}$ The samples all
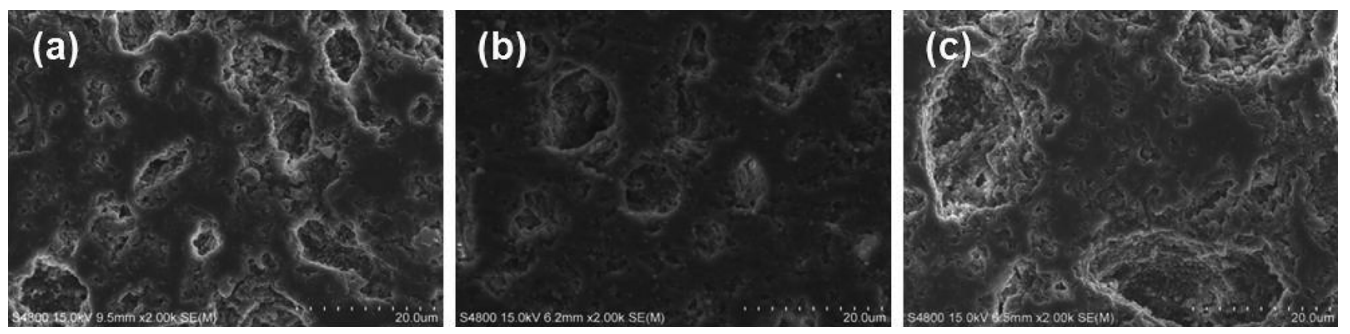

Fig. 1. Microstructures of fabricated samples with different size of graphite added: (a) 15.35 , (b) 19.42 , and (c) $22.32 \mu \mathrm{m}$. 

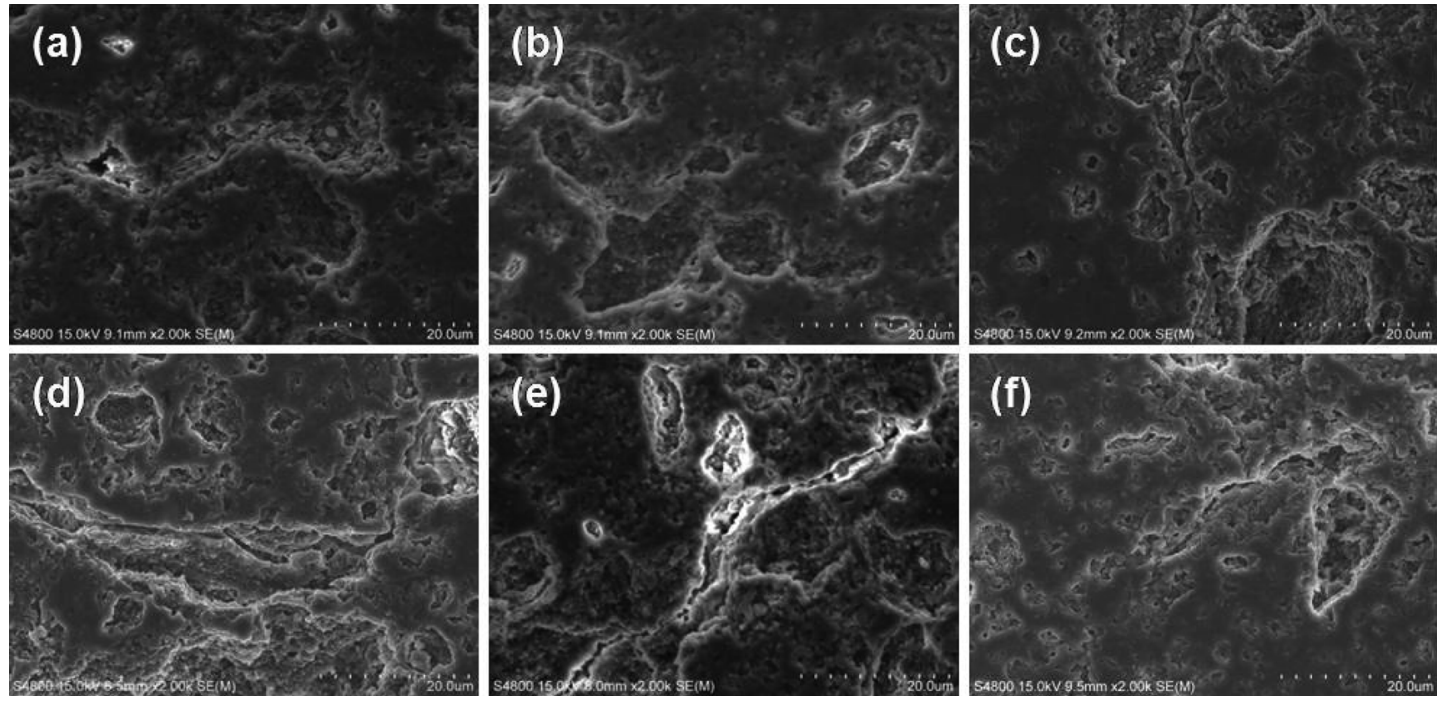

Fig. 2. Morphology of samples A, B, and C (respectively) after thermal shock test at $600^{\circ} \mathrm{C}(\mathrm{a}),(\mathrm{b}),(\mathrm{c})$ and at $900^{\circ} \mathrm{C}(\mathrm{d})$, (e), (f).

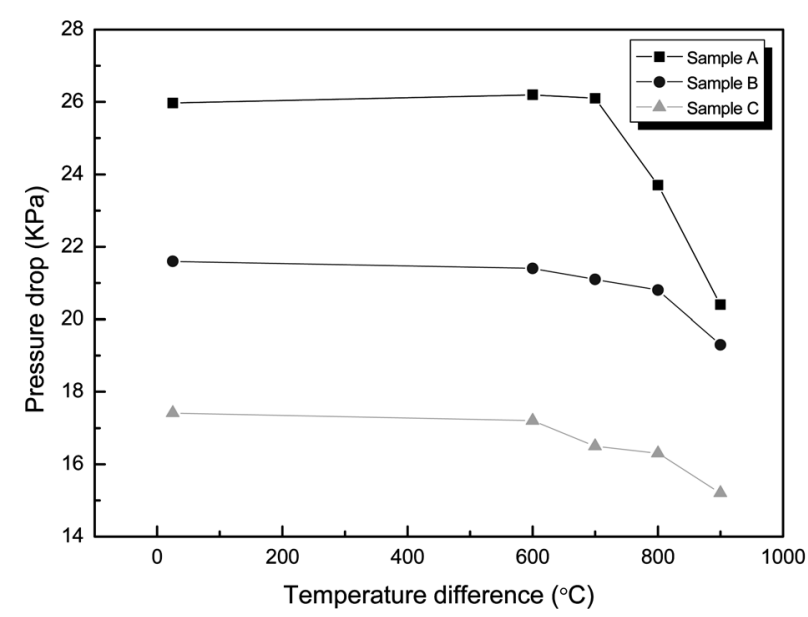

Fig. 3. Pressure drop of porous nozzle samples with different pore size and flow velocity with increasing $\Delta \mathrm{T}$.

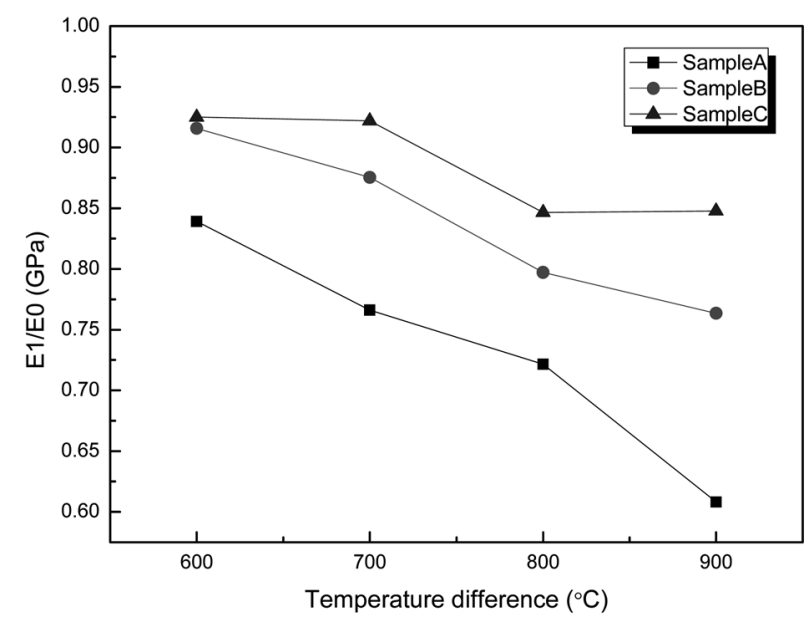

Fig. 4. Effect of quenching temperature difference $(\Delta \mathrm{T})$ on the E1/E0 ratio. have virtually the same porosity, but they show large differences in pressure drop depending on the pore size. The results which showed low pressure drop might be attributed to the rapid change of internal fluid flow, which could increas the rate of thermal shock relaxation. These results are reasonable for improving the thermal shock resistance. ${ }^{18)}$ After the thermal shock test, the pressure drop of samples A and B sharply changed at $\Delta \mathrm{T}$ of 700 and $800^{\circ} \mathrm{C}$, respectively. But unlike those samples, the pressure drop of sample $\mathrm{C}$ did not critically decrease. According to those results, larger pore size seems to increase the critical temperature $\left(\mathrm{T}_{\mathrm{C}}\right)$ of porous nozzles. In otherwords, when $\mathrm{T}_{\mathrm{C}}$ increases, the material can endure higher temperatures, thus hindering the generation and growth of cracks and improving the thermal shock behavior. This behavior is similar to the crack generation and growth shown in Fig. 2.

The dynamic elastic modulus $\mathrm{E}$ of samples was measured by pulse velocity using an ultrasonic tester. The thermal shock behavior of fabricated samples was evaluated by measuring the decrease in the $\mathrm{E}_{1} / \mathrm{E}_{0}$ ratio, where $\mathrm{E}_{0}$ is the original dynamic elastic modulus and $E_{1}$ is that value after one quenching process. ${ }^{7,15)}$ The elastic modulus $\mathrm{E}$ decreases if any damage exists, such as the formation of new cracks or propagation of existing ones. ${ }^{7)}$ Table 1 shows the $\mathrm{E}_{0}$ values of sample A, B, and C are 8.94, 8.73, and $10.81 \mathrm{GPa}$, respectively. The ratio of $\mathrm{E}_{1} / \mathrm{E}_{0}$ showed certain differences among the three samples as the temperature differences increased. Sample A, which has the smallest pore size, has a linear decrease from $\Delta \mathrm{T}$ of $600^{\circ} \mathrm{C}$ and lower values than the other samples throughout the range of temperatures, whereas sample $\mathrm{B}$ and $\mathrm{C}$ descended only $15 \sim 20 \%$. In particular, $\mathrm{E}_{1} / \mathrm{E}_{0}$ of sample $\mathrm{C}$ decreased less in all temperature ranges, showed only a $15 \%$ degradation even at $\Delta \mathrm{T}$ of $900^{\circ} \mathrm{C}$. This result indicates that, with constant porosity, larger pores could enhance the elastic modulus of porous nozzles. All of these results suggest that porous ceramics with well dispersed large pores show 
improved thermal shock behavior, just as they show higher porosity.

\section{Conclusion}

In this paper, the effects of pore size of porous nozzles on thermal shock behavior were investigated. As the size of graphite increases, the pore size and distance between the pores also increases. Thus, the flexural strength was also improved, because the greater distance between pores enhances the resistance to stress. After themal shock tests, the critical temperature $\left(\mathrm{T}_{\mathrm{C}}\right)$ could be estimated according to variations in pressure drop, was shown to increase in accordance with increasing pore size. For the elastic modulus, the sample with the largest pore size experiences the smallest decrease of the values from the first state. These results were confirmed by microstructure analysis, which illustrated that the sample with larger pore size grew fewer cracks. Consequently, all of our results suggest that, with constant porosity, larger pore size can enhance the thermal shock resistance of porous nozzles, thus allowing for more opportunities to design porous ceramics for severe temperature conditions.

\section{Achknowledgment}

This research was supported by a grant from the Fundamental R\&D Program for Core Technology of Materials funded by the Ministry of Knowledge Economy (M-2009-010028).

\section{REFERENCES}

1. G. J. Zhang, J. F. Yang, and Tatsuki Ohji, "Fabrication of Porous Ceramics with Unidirectionally Aligned Continuous Pores," J. Am. Ceram. Soc., 84 [6] 1395-7 (2001).

2. F. Tang, H. Fudouzi, T. Uchikoshi, and Y. Sakka, "Preparation of Porous Materials with Controlled Pore Size and Porosity," J. Eur. Ceram. Soc., 24 341-4 (2004).

3. K. Maca, P. Dobsak, and A.R. Boccaccini, "Fabrication of Graded Porous Ceramics using Alumina-carbon Powder Mixtures," Ceram. Int., 27 577-84 (2001).

4. O. Lyckfeldt and J. M. K. Ferreira, "Processing of Porous Ceramics by 'Starch Consolidation'," J. Eur. Ceram. Soc., 18 131-40 (1998).

5. C. Yuan, L. J. Vandeperre, R. J. Stearn, and W. J. Clegg,
"The Effect of Porosity in Thermal Shock," J. Mater. Sci., 43 4099-106 (2008).

6. M. Collin and D. Rowcliffe, "Analysis and Prediction of Thermal Shock in Brittle Materials," Acta Mater., 48 165565 (2000).

7. N. M. Rendtorff, L. B. Garrido, and E. F. Aglietti, "Effect of the Addition of Mullite-zirconia to the Thermal Shock Behavior of Zircon Materials," Mater. Sci. Eng. A., 498 208-15 (2008).

8. T. Volkov-Husovic, R. M. Jancic, M. Cvetkovic, D. Mitrakovic, and Z. Popovic, "Thermal Shock Behavior of Alumina-Based Refractories: Fracture Resistance Parameters and Water Quench Test," Mater. Lett., 38 372-8 (1999).

9. J. H. She, J. F. Yang, and T. Ohji, "Thermal Shock Resistance of Porous Silicon Nitride Ceramics," J. Mater. Sci. Lett., 22 331-3 (2003).

10. D. P. H. Hasselman, "Unified Theory of Thermal Shock Fracture Initiation and Crack Propagation in Brittle Ceramics," J. Am. Ceram. Soc., 52 [11] 600-4 (1969).

11. D. P. H. Hasselman and J. P. Singh, "Analysis of Thermal Stress Resistance of Microcracked Brittle Ceramics," Am. Ceram. Soc. Bull., 58 856-60 (1979).

12. S. H. Yoon, M. K. Cho, D. H. Jeong, and H. S. Lee, "Effect of Porosity on Durability in a Porous Nozzle for Continuous Casting (in Korean)," Kor. J. Met. Mater., 48 [7] 625-9 (2010).

13. Y. H. Cho, J. Y. Kim, S. H. Yoon, and H. S. Lee, "Effect of the Pore Size of Graphite on the Mechanical Properties and Permeability of a Porous Nozzle for Continuous Casting Process," Kor. J. Met. Mater., 49 [7] 530-4 (2011).

14. Z. Wang, C. Hong, X. Zhang, X. Sun, and J. Han, "Microstructure and Thermal Shock Behavior of $\mathrm{ZrB}_{2}-\mathrm{SiC}$-graphite Composite," Mater. Chem. Phys., 113 338-41 (2009).

15. N. Rendtorff, L. Garrido, and E. Aglietti, "Mullite-zirconiazircon Composites: Properties and Thermal Shock Resistance," Ceram. Int., 35 779-86 (2009).

16. J. T. Richardson, Y. Peng, and D. Remue, "Properties of Ceramic Foam Catalyst Supports: Pressure Drop," Appl. Catal., A, 204 19-32 (2000).

17. K. Ishizaki, S. Komarneni, and M. Nanko, Porous Materials, pp. 202-24, Kluwer Academic Publishers, Netherlands, 1998.

18. L. Shen, M. Liu, X. Liu, and B. Li, "Thermal Shock Resistance of the Porous $\mathrm{Al}_{2} \mathrm{O}_{3} / \mathrm{ZrO}_{2}$ Ceramics Prepared by Gelcasting," Mater. Res. Bull., 42 2048-56 (2007).

19. R. W. Rice, "Comparison of Stress Concentration Versus Minimum Solid area Based Mechanical Property-porosity Relation,” J. Mater. Sci., 28 2187-90 (1993). 